\title{
The economic burden of prostate cancer - a Swedish prevalence-based register study
}

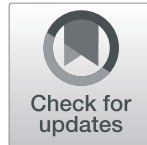

Shuang Hao ${ }^{1 *}$ (D), Ellinor Östensson ${ }^{1,2}$, Martin Eklund ${ }^{1}$, Henrik Grönberg ${ }^{1}$, Tobias Nordström ${ }^{1,3}$, Emelie Heintz ${ }^{4}$ and Mark Clements ${ }^{1}$

\begin{abstract}
Background: Incidence and prevalence of prostate cancer in Sweden have increased markedly due to prostatespecific antigen (PSA) testing. Moreover, new diagnostic tests and treatment technologies are expected to further increase the overall costs. Our aims were (i) to estimate the societal costs for existing testing, diagnosis, management and treatment of prostate cancer, and (ii) to provide reference values for future cost-effectiveness analyses of prostate cancer screening and treatment.
\end{abstract}

Methods: Taking a societal perspective, this study aimed to investigate the annual cost of prostate cancer in Sweden using a prevalence-based cost-of-illness approach. Resource utilisation and related costs within Stockholm Region during 2016 were quantified using data from the Stockholm PSA and Biopsy Register and other health and population registers. Costs included: (i) direct medical costs for health care utilisation at primary care, hospitals, palliative care and prescribed drugs; (ii) informal care; and (iii) indirect costs due to morbidity and premature mortality. The resource utilisation was valued using unit costs for direct medical costs and the human capital method for informal care and indirect costs. Costs for the Stockholm region were extrapolated to Sweden based on cancer prevalence and the average costs by age and resource type.

Results: The societal costs due to prostate cancer in Stockholm in 2016 were estimated to be $€ 64$ million Euro $(€ \mathrm{Mn})$, of which the direct medical costs, informal care and productivity losses represented 62,28 and $10 \%$ of the total costs, respectively. The total annual costs extrapolated to Sweden were calculated to be $€ 281 \mathrm{Mn}$. The average direct medical cost, average costs for informal care and productivity losses per prevalent case were $€ 1510$, $€ 828$ and $€ 271$, respectively. These estimates were sensitive to assumptions related to the proportion of primary care visits associated with PSA testing and the valuation method for informal care.

Conclusion: The societal costs due to prostate cancer were substantial and constitute a considerable burden to Swedish society. Data from this study are relevant for future cost-effectiveness evaluations of prostate cancer screening and treatment.

Keywords: Costs-of-illness, Prostate cancer, Prostate-specific antigen test, Sweden

\section{Background}

Globally in 2018, prostate cancer (PCa) was the second most frequent cancer diagnosed and the fifth leading

\footnotetext{
* Correspondence: shuang.hao@ki.se

${ }^{1}$ Department of Medical Epidemiology and Biostatistics, Karolinska Institutet, Nobels väg 12A, 17165 Stockholm, Sweden

Full list of author information is available at the end of the article
}

cause of cancer death in males [1]. In Sweden, the availability of prostate-specific antigen (PSA) testing has led to increased incidence rates and a gradual decline in mortality rates $[2,3]$. However, PCa is the most common cause of cancer death among Swedish men $[4,5]$. One consequence of the combination of increased incidence, long lead-times associated with testing, and good

(c) The Author(s). 2020 Open Access This article is licensed under a Creative Commons Attribution 4.0 International License, which permits use, sharing, adaptation, distribution and reproduction in any medium or format, as long as you give appropriate credit to the original author(s) and the source, provide a link to the Creative Commons licence, and indicate if changes were made. The images or other third party material in this article are included in the article's Creative Commons licence, unless indicated otherwise in a credit line to the material. If material is not included in the article's Creative Commons licence and your intended use is not permitted by statutory regulation or exceeds the permitted use, you will need to obtain permission directly from the copyright holder. To view a copy of this licence, visit http://creativecommons.org/licenses/by/4.0/ The Creative Commons Public Domain Dedication waiver (http://creativecommons.org/publicdomain/zero/1.0/) applies to the data made available in this article, unless otherwise stated in a credit line to the data. 
survival for localised $\mathrm{PCa}$ is that the prevalence of $\mathrm{PCa}$ has increased markedly. In 2016, approximately 25,000 and 110,000 males were living with a diagnosis of PCa in Stockholm and Sweden [5], accounting for 2.3 and 2.1\% of the male population, respectively.

Although PSA has been commonly used as a screening test for PCa [6], the balance between the benefits and harms of PSA testing has been debated. The European Randomized Study of Screening for PCa found a mortality reduction of $20 \%$ after 16 -year follow-up from PSA testing compared with no testing [7]. However, PSA testing is also associated with potential harms, including unnecessary biopsies, over-diagnosis of low-risk cancers and over-treatment $[4,5]$. Unnecessary biopsies and over-diagnosis may not only reduce health-related quality of life of the patients, but they are also associated with increased costs due to increased health-care visits, biopsy-related complications, over-treatment and lost productivity [4].

Complementary diagnostic tools may reduce the harms and increase the health benefits from early detection. In recent years, risk assessment using Magnetic Resonance Imaging (MRI) together with MRI-targeted biopsies has improved specificity and sensitivity for high risk $\mathrm{PCa}[8,9]$. Although the cost of prostate MRI has declined with increased use of abbreviated MRI protocols, using MRI with targeted biopsies is associated with increased costs compared with traditional biopsy procedures.

For the treatment of low-risk $\mathrm{PCa}$, active surveillance (AS) has been recommended by Swedish clinical guidelines since 2007 [10]. For intermediate- and high-risk PCa patients, radical prostatectomy (RP) and radiation therapy (RT) are common treatment modalities. In 2016, 98.1\% of all RP procedures in public hospitals were robot-assisted in Stockholm [11], which are associated with $10-42 \%$ higher costs than open surgery [12]. For localised high-risk patients, a combination of RT and adjuvant androgen deprivation is mostly used with curative intent. For recurrent and metastatic PCa patients, the first-line treatment is hormone therapy (or androgen deprivation therapy). Two recent drugs, Abiraterone and Enzalutamide, have a newer mechanism of action and a more convenient form of administration; however they are associated with high costs.

Previous cost-of-illness (COI) studies performed in Sweden estimated that the total costs due to PCa for the years 1985, 1993 and 1998 were 51 million Euro (€Mn), $€ 86 \mathrm{Mn}$ and $€ 109 \mathrm{Mn}$ (not adjusted by the consumer price index (CPI)) respectively, with a $10 \%$ annual increase between 1985 and 1998. However, these studies were based on small cohorts and only considered health care utilisation [13-16].

Costs due to PCa from a societal perspective have been estimated in two studies in the past decade. In a
European population-based cost study from 2009 for major cancer sites, the total cost for PCa in Sweden was estimated to be $€ 237 \mathrm{Mn}$ [17]. However, many of the calculations for Sweden were based on assumptions or data from other countries or using European level data [17]. In a 2013 report in Swedish, the costs were estimated to be $€ 321 \mathrm{Mn}$ [18]. This study employed data from multiple health registers, with assumptions from clinical experts as well as a regional price list. However, in both studies, details and assumptions were incompletely reported, including the diagnosis-related groups (DRGs) that were used to calculate inpatient and outpatient costs, a full drug list for treating $\mathrm{PCa}$, separate costs of the prescribed (pharmacy-based) and requisition (hospital-based) drugs, as well as unit costs for each type of resource.

This study aimed to (i) estimate the annual economic burden of $\mathrm{PCa}$ in the Stockholm region and Sweden in 2016 and (ii) provide reference values for future costeffectiveness analyses of PCa screening and treatment.

\section{Methods}

As per economic evaluations for the Swedish Dental and Pharmaceutical Benefits Agency (TLV) [19] and recommendations from previous studie, all costs to society should be taken into account when conducting a costof-illness study for making decisions about the resource allocation [20-22]. In this prevalence-based cost-ofillness study, the total annual cost of $\mathrm{PCa}$ was estimated using a societal perspective. We used a bottom-up approach to estimate the economic burden [23]. Direct and indirect costs during 2016 were estimated in three steps, including (i) the identification of categories of resource use, (ii) quantification of resources use, and (iii) valuation of the identified resources [24]. The total costs for PCa in Stockholm were calculated by multiplying the identified quantities of resource use with the unit costs of each resource. Costs were adjusted for inflation by using the CPI [25] and converted to 2016 Euros (mean annual exchange rate $€ 1=9.47$ Swedish Krona) [26]. To calculate a national cost, the results were extrapolated to males in Sweden. Data were analysed using SAS version 9.4 .

\section{Study population}

The study population included all males residing in the Stockholm region at the end of 2015 using the Stockholm PSA and Biopsy Register (SPBR), which has linked all PSA tests and prostate biopsies from the laboratories serving the Stockholm region to multiple health and population registers in Sweden. For the biopsies, this includes both negative biopsies and biopsies indicating PCa. Those who have left Stockholm Region during 2016 would have under-reported PSA tests and 
biopsies. The linked registers include: the National Prostate Cancer Register; the National Cancer Register; the Total Population Register; the National Patient Register, including inpatient and outpatient events; the National Death Register; and the National Prescribed Drug Register (PDR) [27].

\section{Direct medical costs}

\section{Inpatient and outpatient care}

By using the SPBR, the numbers of events from inpatient care and outpatient care were identified using the Nordic Diagnostic Related Groups Swedish DRG classification system. The International Classification of Diseases, 10th version (ICD-10) code C61.9 was used to identify cases related to $\mathrm{PCa}$ as the primary diagnosis together with Swedish DRG codes associated with PCa related events. For details of the event identification, see Appendix A. The unit costs for each DRG were extracted from the Stockholm region price list [28]. The costs for inpatient and outpatient care were calculated by the number of DRGs multiplied by the unit costs.

\section{Primary care}

Resources utilised in primary care were based on PSA tests recorded from the SPBR. For each PSA test, if the sample date was not performed during inpatient care and not on the same date as an outpatient care, it was considered as being conducted in primary care. Furthermore, PSA tests undertaken prior to a diagnosis of $\mathrm{PCa}$ were categorised as diagnostic tests, and PSA tests undertaken on the same date or after the diagnosis of a $\mathrm{PCa}$ were categorised as monitoring tests. A large proportion of primary care visits for patients who had a PSA test may not be associated with PCa testing alone. As per an earlier report, we assumed that $20 \%$ of the consultation cost with a PSA test was associated with PCa testing [29]. The average unit cost of a primary care visit was based on data for the Stockholm region in 2014 from the National Board of Health and Welfare (NBHW) [30] and the growth rate of the unit cost from the Southern Health Region's price lists in 2015 and 2016 [31, 32]. For PSA tests, a test analysis cost was added to the costs for the primary care visit [33]. The costs for primary care were calculated by the number of visits due to diagnostic and monitoring testing, multiplied by the unit costs.

\section{Pharmaceutical costs}

Thirteen prescribed drugs and hospital-based requisition drugs (substances, see Appendix B1 for a drug list) were used in Sweden for treating PCa [34-37]. We extracted aggregated costs at the fifth level of the Anatomical Therapeutic Chemical Classification System (ATC5) from the Concise Database of the Swedish eHealth
Agency [37] for the Stockholm region. For prescribed drugs with multiple indications, we used the PDR to identify the proportion of drug uses by males aged 18 and above [37] and the SPBR to estimate the proportion of drug uses for PCa. For requisition drugs used for multiple indications, data from the Stockholm Electronic Patient Records (SEPR) Corpus Health Bank from Stockholm University $[38,39]$ were extracted to estimate $\mathrm{PCa}$ associated costs. Counts of drug use by brand, age and sex were multiplied by the unit costs from The Dental and Pharmaceutical Benefits Agency (TLV) drug database [40]. Appendix B2 illustrates the steps in the cost calculations.

\section{Palliative care}

To estimate the costs of palliative care due to $\mathrm{PCa}$, data from the Swedish Register of Palliative Care (SRPC) were linked to the SPBR. The data in SRPC were primarily collected from an end-of-life questionnaire, which contains 30 questions usually completed by healthcare staff after a patient's death [41]. In the questionnaire, the "place of death" indicated the type of care that a patient received [41]. As palliative care inside the hospital ward was captured by inpatient care (see Appendix C1), we restricted data to the care taken place at the hospice/palliative inpatient care, the nursing home, or the patient's home. The total number of days in each type of palliative care and the total number of patients were calculated. The unit costs per day in each type of care were extracted from existing studies [42-44] and calculated to year 2016 using CPI. The total costs due to palliative care were calculated by summing up the products of the total number of care days and the cost per day of each type of care. See Table 2 and Appendix C2 for details.

\section{Informal care}

The measurement of resource use (numbers of hours) for informal care was conducted using existing and published data from WAVE2 and WAVE3 of the Survey of Health, Ageing and Retirement in Europe (SHARE) project [47]. The participants in WAVE2 were asked whether they were severely limited in daily activities and other questions regarding the care received inside or outside the household. In WAVE3, the proxy respondents such as partner, child or other relationship with the deceased person answered a series of questions regarding the care provided to the patients in the last 12 months before their deaths. For details of the proxies, see Appendix D2. We used the information from WAVE2 and WAVE3 to estimate the age-specific hours of informal care for patients severely limited in daily activities and patients that were terminally ill. Logistic regressions were applied to estimate the probability of being severely limited in daily activities and the 
probability of receiving informal care due to cancer. Linear regressions were used to estimate the hours of care received and the probability of caregivers at working age. See Appendix D1-6 for details. We assumed caregivers at working age provided care during work hours and followed similar assumptions to those used in the European study and a Swedish report $[17,18]$ to decide what type of caregiver is at working age (see Appendix D4 and D6). Following recommendations for health economic evaluations, we applied the annual general gross wage rate for all working individuals of both genders $[24,50]$, which was $€ 56,930$ including social security contributions $(36.98 \%)[25,51]$ in 2016. Based on 253 workdays and an 8-h work day (full time), the cost per hour was estimated to be $€ 28.1$. The total costs for informal care were multiplied by the estimated hours of care and cost per hour.

\section{Productivity losses}

We used the human capital method to estimate the costs following a diagnosis of PCa related to lost productivity due to morbidity (sick leave and early retirement) and mortality (premature death). We valued lost productivity in terms of gross earnings [52] and assumed full employment through to the general retirement age 65 years in Sweden. Using the average annual gross earnings for both genders in Sweden in year 2016, the cost of a full work day was estimated to be $€ 225.0$.

\section{Productivity losses due to morbidity}

The number of men with a primary cancer diagnosis code of ICD-10 C61 during 2016 in Stockholm and the number of days on long-term sick leave (more than 14 days) and early retirement were retrieved from the Swedish Social Insurance Agency (Försäkringskassan, abbreviated FSK). The diagnosis code used by FSK was primarily based on a medical certificate completed by a general practitioner. The men identified from FSK were linked to the cohort using anonymised IDs. In Sweden, individuals can receive $100,75,50 \%$ or $25 \%$ cash benefit if a long-term sick leave is taken. Short-term sick leave (14 days or less) is covered by the employer and is not reported to FSK. For patients who had long-term sick leave, we assumed that a $100 \%$ short-term sick leave was taken. For people aged 30-64 years, a sickness compensation can be granted if their work capacity is permanently impaired and proportional compensation also applies to early retirement [53]. To estimate the cost of lost productivity due to morbidity, the total number of net workdays lost due to sick leave and early retirement was multiplied by the average daily income for full-time employees.

\section{Productivity losses due to premature death}

We extracted the number of males that died from PCa during 2016 in Stockholm and their age of death from the SPBR. For each deceased male, the accumulated losses of years were calculated by integrating the population-based survival rate from the patient's age of death through to age 65 years [54]. Costs for future productivity losses were discounted at 3\% yearly in accordance with international and Swedish recommendations $[19,50]$. See Appendix E for details on these calculations.

\section{Extrapolation to Sweden}

The annual costs due to PCa in Stockholm were extrapolated to Sweden based on the average annual costs per prevalent case for each type of resource in Stockholm by 10-year age groups multiplied by the number of prevalent cases in Sweden in each age group extracted from Nordcan [5]. For productivity losses due to premature mortality, the average cost per death was multiplied by the number of PCa deaths in Sweden. See Appendix F for the pattern of prevalence, incidence and mortality in Stockholm and Sweden through to 2016.

\section{Sensitivity analyses}

Sensitivity analyses were performed to address the uncertainty in key parameters. First, records show that 87\% of cancer deaths in Sweden were reported to SRPC in 2015 [41]. Therefore, the potential palliative care for the PCa patients who were recorded in the SPBR but not reported to the SRRC in 2016 was considered in a sensitivity analysis (see Appendix C2). Second, primary care of men who had PSA tests without diagnoses of PCa were not considered in the European study and the Swedish report. The corresponding costs were excluded in a sensitivity analysis. Third, we estimated the costs for informal care using the proxy good method, which values the care at a market price, considering the care would have been provided by a formal caregiver [50, 55-58]. We applied the hourly cost at a nursing home as a proxy at $€ 26.1$ [42] to the total hours calculated, irrespective of whether the care was provided by someone at a working age or not. Lastly, the unit cost of prostate biopsies from the price list in the base case may be lower than the cost to a clinical department. A unit cost at $€ 1159$ (Biopsy at outpatient care: w/o MRI, Table 4) was used to investigate the effect of this uncertainty.

\section{Illustration and costs for different diagnosis and treatment pathway}

Resource use in the diagnosis phase, active surveillance, treatment phase and post-treatment follow-up was described for the clinical guidelines in Sweden [59] and estimated for standardised pathways. 


\section{Results}

We present (i) detailed results for the Stockholm region, (ii) aggregated results for Sweden, (iii) sensitivity analyses and (iv) a description of costs by treatment pathways.

\section{Prevalence, incidence and mortality in the Stockholm region}

In total, there were 1772 incident cases of $\mathrm{PCa}$ in 2016, which were $7.0 \%$ of the 25,490 prevalent patients (Table 1). Of the 995 prevalent cases who died in 2016, $38.8 \%$ died from PCa. In summary, PCa was uncommon before the age of 50 years, incidence rates were highest among those aged 70-79 years, and prevalence was highest among those aged $80-89$ years. Mortality rates for $\mathrm{PCa}$ increased rapidly with increasing age.

\section{Direct medical costs}

Inpatient and outpatient care

Ten PCa-related DRGs were identified for 1602 patients from inpatient care (Table 2); $45.8 \%$ of those patients were aged 70-79 years. Radical prostatectomy was the most frequent DRG with the highest cost of over $€ 6.9 \mathrm{Mn}$, contributing to $66.4 \%$ of the total costs for inpatient care. We identified 4841 patients with resource utilisation in outpatient care from eight DRGs (Table 2). Over $60 \%$ of the costs of outpatient care were associated with radiation therapy, with an annual estimated cost of more than $€ 6.3 \mathrm{Mn}$. Of the 3956 episodes of prostate biopsies (N75O, Table 2), approximately $45 \%$ were undertaken as diagnostic biopsies (that is, with no prior prostate cancer diagnosis) and 55\% were conducted after a prostate cancer diagnosis.

\section{Primary care}

Costs directly associated with PSA testing accounted for $7.5 \%$ of the total costs for PCa. Approximately $73 \%$ of the PSA tests were undertaken as diagnostic testing. On average, PCa patients conducted 2.0 PSA tests for monitoring the disease in 2016 (Table 2).

\section{Pharmaceutical costs}

Of the 13 substances listed (Table 2), Bicalutamide was the most frequently prescribed drug, used by approximately 3100 patients (Table 2). Cabazitaxel accounted for over half of the total requisition drug costs $(€ 1.1 \mathrm{Mn})$. The antiandrogens Enzalutamide and Abiraterone had an annual cost of $€ 4.8 \mathrm{Mn}$ and $€ 1.2 \mathrm{Mn}$, respectively, accounting for $57 \%$ of the total drug costs due to $\mathrm{PCa}$ in the Stockholm region in 2016.

\section{Palliative care}

Among the 386 deaths due to PCa in 2016 (Table 1), 267 deaths were reported to SRPC. Of these patients, 228 received palliative care other than hospital inpatient care (Table 2) with an average direct cost of $€ 16,441$ per patient. The patients who died in hospice or palliative inpatient care stayed on average for 18 days. Patients with home support by a specialised home-care team had an average length of 58 days. Nursing home based patients had an average of 125 and 36 days with permanent or short-term stays, respectively.

\section{Informal care}

For patients who were severely limited in daily activities, informal care was primarily provided by relatives or friends outside the household (83\%), with approximately $1 \mathrm{~h}$ per day of the help. This value reduced to $0.5 \mathrm{~h}$ per day when restricted to caregivers aged less than 65 years. The average time for informal care provided by someone inside the household was approximately $1.1 \mathrm{~h}$ per day, of which $0.6 \mathrm{~h}$ per day were provided by caregivers aged less than 65 years. For patients who were terminally ill, almost $4 \mathrm{~h}$ of informal care were provided per day, of

Table 1 Description of the study population by 10-year age group, Stockholm Region, 2016

\begin{tabular}{|c|c|c|c|c|c|c|c|c|c|c|}
\hline \multirow{2}{*}{$\begin{array}{l}\text { Age } \\
\text { (Years) }\end{array}$} & \multicolumn{2}{|c|}{ Men in Stockholm } & \multicolumn{2}{|c|}{ Age-specific Prevalence-PCa } & \multicolumn{2}{|c|}{ Incidence-PCa } & \multicolumn{2}{|c|}{ Mortality-all cause } & \multicolumn{2}{|c|}{ Mortality-PCa } \\
\hline & No. & $\%$ of Total & No. & $\%$ by age & No. & Rate per 1000 & No. & Rate per 1000 & No. & Rate per 1000 \\
\hline $0-9$ & 130,411 & $12.0 \%$ & & $0.0 \%$ & & 0.00 & & 0.00 & & 0.00 \\
\hline $10-19$ & 116,537 & $10.7 \%$ & & $0.0 \%$ & & 0.00 & & 0.00 & & 0.00 \\
\hline $20-29$ & 140,326 & $12.9 \%$ & & $0.0 \%$ & & 0.00 & & 0.00 & & 0.00 \\
\hline $30-39$ & 169,731 & $15.6 \%$ & & $0.0 \%$ & & 0.00 & & 0.00 & & 0.00 \\
\hline $40-49$ & 163,090 & $15.0 \%$ & 134 & $0.1 \%$ & 31 & 0.19 & & 0.00 & & 0.00 \\
\hline $50-59$ & 141,519 & $13.0 \%$ & 1868 & $1.3 \%$ & 252 & 1.78 & 6 & 0.04 & 6 & 0.04 \\
\hline $60-69$ & 108,005 & $10.0 \%$ & 7297 & $6.8 \%$ & 601 & 5.56 & 87 & 0.81 & 43 & 0.40 \\
\hline 70-79 & 79,506 & $7.3 \%$ & 11,079 & $13.9 \%$ & 692 & 8.70 & 289 & 3.63 & 122 & 1.53 \\
\hline 80-89 & 29,330 & $2.7 \%$ & 4365 & $14.9 \%$ & 176 & 6.00 & 420 & 14.32 & 148 & 5.05 \\
\hline $90+$ & 6605 & $0.6 \%$ & 747 & $11.3 \%$ & 20 & 3.03 & 193 & 29.22 & 67 & 10.14 \\
\hline Total & $1,085,060$ & $100.0 \%$ & 25,490 & $2.3 \%$ & 1772 & 1.63 & 995 & 0.92 & 386 & 0.36 \\
\hline
\end{tabular}


Table 2 Unit costs and quantity of resource utilization due to PCa, Stockholm region, 2016 (€)

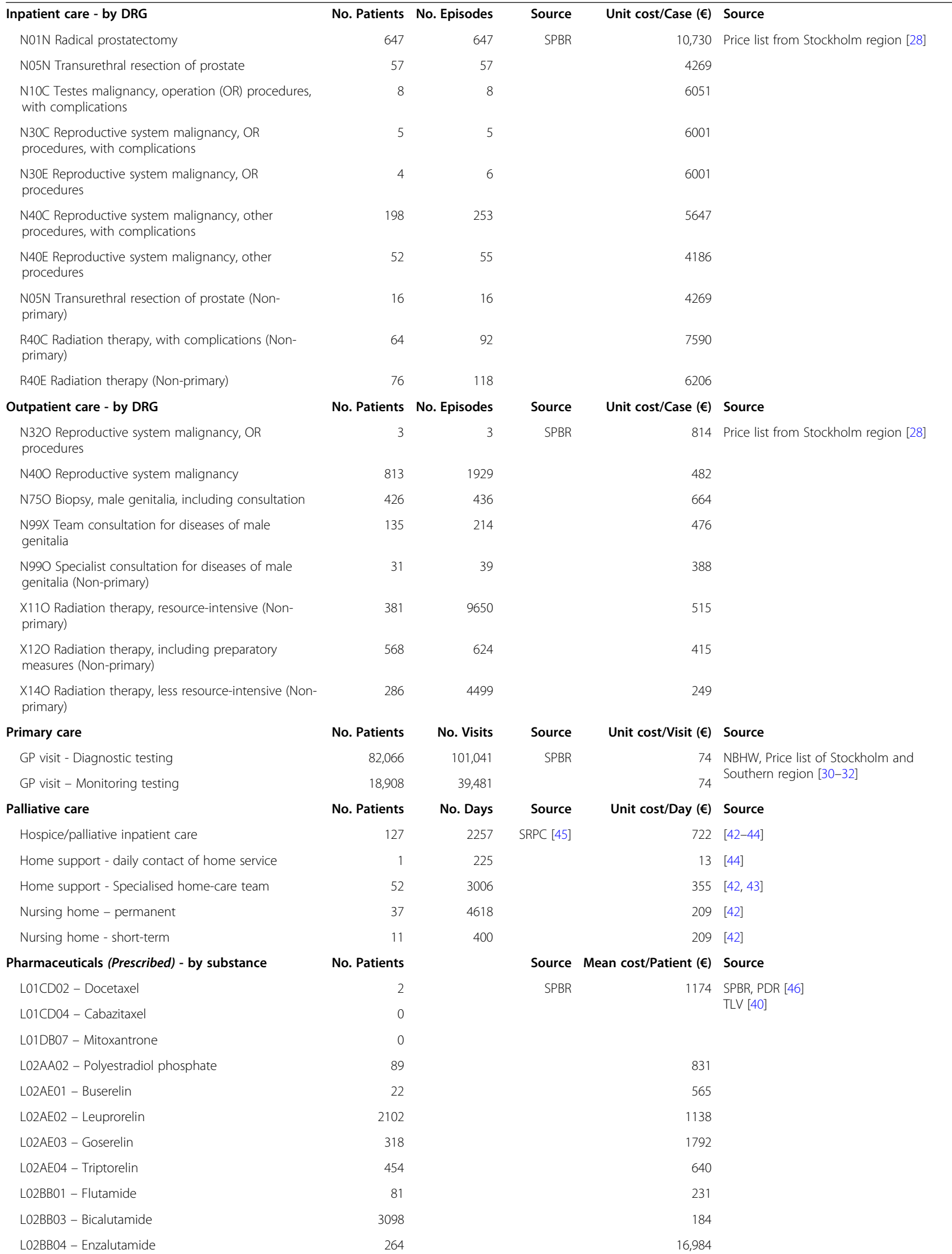


Table 2 Unit costs and quantity of resource utilization due to PCa, Stockholm region, 2016 (€) (Continued)

\begin{tabular}{|c|c|c|c|c|c|}
\hline L02BX02 - Degarelix & 4 & & & 326 & \\
\hline L02BX03 - Abiraterone & 78 & & & 15,416 & \\
\hline Informal care & No. Patients & No. Hours & Source & Mean salary/Hour $(€)$ & Source \\
\hline Severely limited in daily activity - outside & 2530 & 495,558 & SHARE [47], & 28 & SCB [48] \\
\hline Severely limited in daily activity - inside & 439 & 98,979 & & 28 & \\
\hline Terminally ill & 153 & 49,697 & & 28 & \\
\hline Productivity losses - morbidity & No. Patients & No. Days & Source & Mean salary/Day $(€)$ & Source \\
\hline Short-term sick leave & 265 & 17,893 & FSK & 225 & SCB [48] \\
\hline Long-term sick leave & 7 & 1649 & & 225 & \\
\hline Productivity losses - pre-mature mortality & No. Patients & No. Years & Source & Gross earning/Year $(€)$ & Source \\
\hline Pre-mature mortality & 17 & 4.32 & $\begin{array}{r}\text { SPBR, } \\
\text { NBHW [49] }\end{array}$ & 56,930 & SCB [48] \\
\hline
\end{tabular}

DRG Diagnosis related group, FSK Swedish Insurance Agency, GP General Practitioner, NBHW National Board of Health and Welfare, OR operation, PDR Prescribed Drugs Register, SCB Statistics Sweden, SHARE Survey of Health, Ageing and Retirement in Europe, SPBR Stockholm PSA and Biopsy Register, SRPC Swedish Register of Palliative Care, TLV Dental and Pharmaceutical Benefits Agency

which approximately $1 \mathrm{~h}$ care per day was provided by caregivers aged less than 65 years.

\section{Productivity losses}

Productivity losses due to sick leave and early retirement were estimated to be $€ 2.8 \mathrm{Mn}$ and $€ 0.3 \mathrm{Mn}$ (Table 3 ). The 265 patients aged 40-64 years were on sick leave for an average of 68 days per person (Table 2), of which 14 days were short-term sick leave paid by the employers. Patients who retired early due to PCa took disability pension for an average of 236 days per person. Seventeen men aged less than 65 years died of $\mathrm{PCa}$ in the Stockholm region during 2016(Table 2). Productivity losses due to premature mortality were estimated to be $€ 3.6 \mathrm{Mn}$ (Table 3 ).

\section{Total costs and extrapolation to Sweden}

The total annual costs due to PCa were estimated to be $€ 65 \mathrm{Mn}$ in Stockholm region and $€ 281 \mathrm{Mn}$ in Sweden (Table 3). The cost per capita in Stockholm was estimated to be $€ 59$, which was higher than the estimated cost at $€ 56$ per male in Sweden. This was partially explained by a higher $\mathrm{PCa}$ prevalence per capita in Stockholm. The largest share of costs were related to health care $(57.9 \%)$ followed by productivity losses (31.7\%) and informal care (10.4\%).

\section{Sensitivity analyses in the Stockholm region}

Sensitivity analyses led to a -5.5 to $+24.7 \%$ change of the total costs in Stockholm in 2016 (Fig. 1). Excluding costs in the primary care setting for men with no prior PCa diagnosis, the total costs decreased markedly by

Table 3 Costs due to PCa by type of resource, Stockholm Region and Sweden, $2016(€)$

\begin{tabular}{|c|c|c|c|c|}
\hline \multirow[t]{2}{*}{ Type of resource } & \multicolumn{2}{|c|}{ Stockholm Region } & \multicolumn{2}{|c|}{ Sweden } \\
\hline & Costs $(€)$ & Costs (\%) & Costs $(€)$ & Costs (\%) \\
\hline Healthcare related costs & $39,765,502$ & $61.6 \%$ & $162,462,861$ & $57.9 \%$ \\
\hline Inpatient care & $10,457,640$ & $16.2 \%$ & $41,041,967$ & $14.6 \%$ \\
\hline Outpatient care & $10,025,188$ & $15.5 \%$ & $40,450,037$ & $14.4 \%$ \\
\hline Primary care & $4,810,643$ & $7.5 \%$ & $17,782,058$ & $6.3 \%$ \\
\hline Palliative care & $3,748,553$ & $5.8 \%$ & $17,914,185$ & $6.4 \%$ \\
\hline Pharmaceuticals & $10,723,478$ & $16.6 \%$ & $45,274,615$ & $16.1 \%$ \\
\hline Informal care & $18,120,816$ & $28.1 \%$ & $89,142,341$ & $31.7 \%$ \\
\hline Productivity losses & $6,626,929$ & $10.3 \%$ & $29,176,618$ & $10.4 \%$ \\
\hline Morbidity - Sick leave & $2,783,210$ & $4.3 \%$ & $8,534,334$ & $3.0 \%$ \\
\hline Morbidity - Early retirement & 256,420 & $0.4 \%$ & 806,630 & $0.3 \%$ \\
\hline Pre-mature mortality & $3,587,299$ & $5.6 \%$ & $19,835,654$ & $7.1 \%$ \\
\hline Total & $64,513,247$ & $100 \%$ & $280,781,820$ & $100.0 \%$ \\
\hline
\end{tabular}


$5.5 \%$. Using the proxy good method to value the informal care doubled the costs for informal care and increased the total costs by $24.7 \%$. Including the costs for those not reported to SRPC and altering the biopsy cost showed minor differences in the total costs.

\section{Illustration and costs for different treatment pathways}

Resource use and the frequency of the resource use for diagnosis, AS, RP, RT, treatment for patients with metastatic $\mathrm{PCa}$, and watchful waiting (WW) are summarised in Fig. 2. The average costs for different treatment pathways are summarised in Table 4. If a patient was referred to outpatient care for a biopsy, the total costs when employing an additional MRI-guided biopsy increased the costs of a biopsy by over $30 \%$ (€1513), compared with using a systematic biopsy $(€ 1159)$. Similarly, use of MRI under AS increased the annual costs by at least $20 \%(€ 704)$. The annual treatment costs for patients with metastatic PCa by using both chemotherapy and hormone therapy (€7283) showed minor differences to using hormone therapy only (€6867).

\section{Discussion}

\section{Main findings}

This study is the first to investigate the economic burden of PCa in Stockholm from a societal perspective.
The annual cost of PCa in Sweden during 2016 was estimated to be $€ 281 \mathrm{Mn}$. Direct medical costs, informal care and productivity losses accounted for approximately 58, 32 and $10 \%$ of the total burden, respectively.

\section{Comparisons with existing evidence and methodological considerations}

Our estimates of the total economic burden are higher than the results from a previous European study [17]. This discrepancy can, in part, be explained by the different estimation methods of the primary care costs; our estimate is more than eight times higher than the costs for primary care in the European study. We estimated the primary care resource utilisation based on the number of visits due to PSA tests, of which $73 \%$ were found to be not associated with a previous $\mathrm{PCa}$ diagnosis. In the European study, resource utilisation of primary care was calculated based on the overall number of visits, the proportion of visits due to all cancers and the proportion of visits due to $\mathrm{PCa}$ [17]. The proportion of visits due to call cancers was estimated from a sample of 26 GPs using electronic health records from Stockholm [60], while the proportion of visits due to $\mathrm{PCa}$ was evaluated indirectly using the proportion of hospital discharge due to PCa out of all cancers [17], which may be biased.

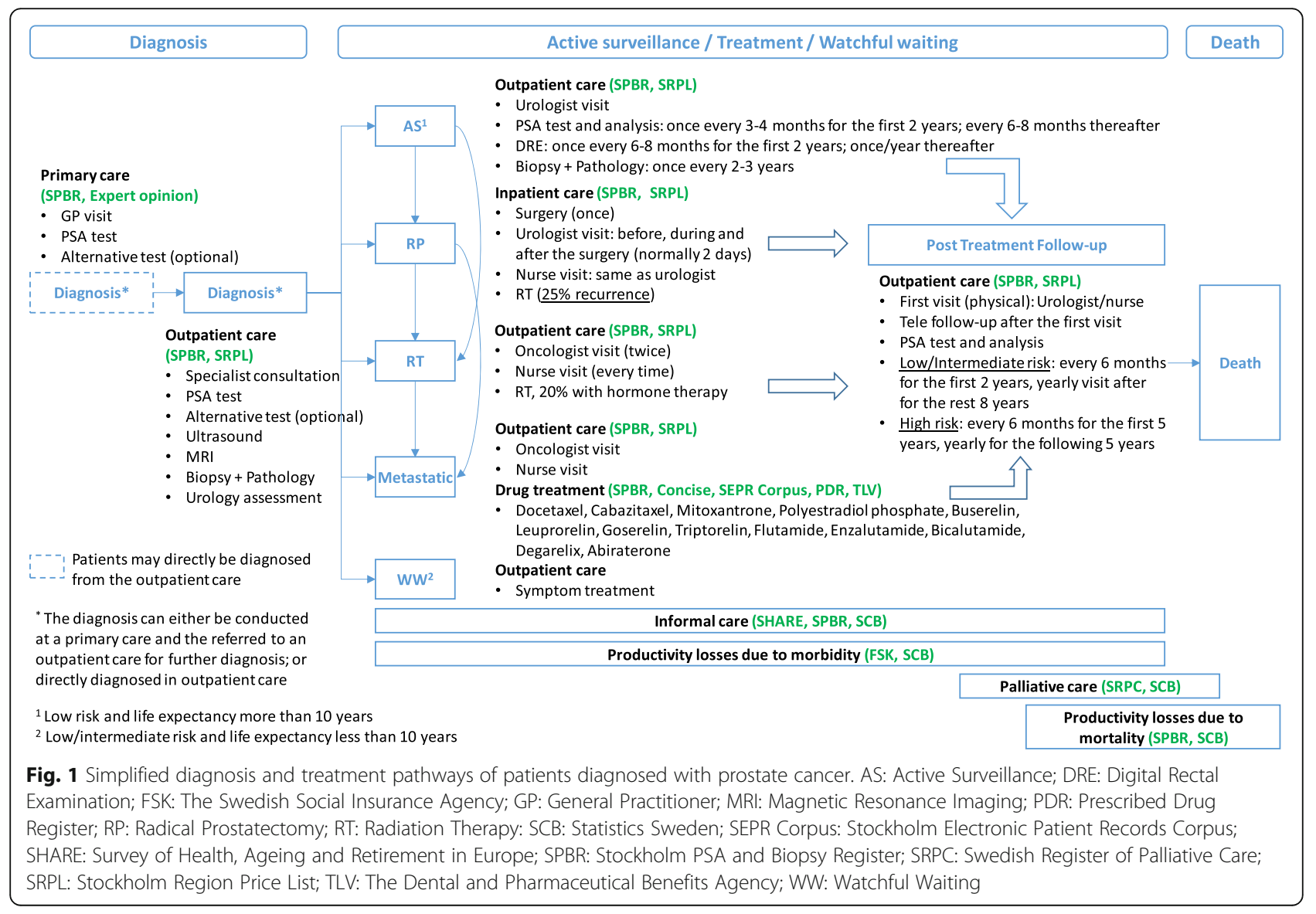




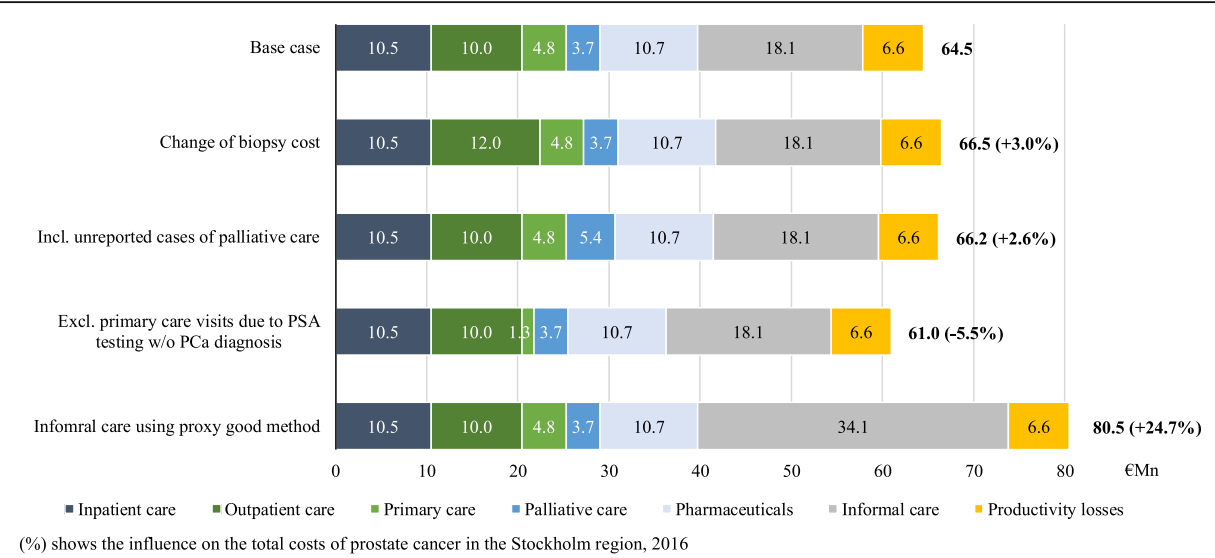

Fig. 2 Sensitivity analyses of costs due to prostate cancer in the Stockholm region (€Mn). (\%) shows the influence on the total costs of prostate cancer in the Stockholm region, 2016

In the European study, costs for accident and emergency care accounted for up to $2 \%$ of the total costs for PCa among all 27 countries [17]. Due to the lack of data, Danish data were used to estimate those costs in Sweden [17]. PCa is less related to the accident and emergency care, while palliative care was measured in our study, where the latter accounted for $6 \%$ of the total costs. Including PCa patients not recorded by SRPC in a sensitivity analysis, the costs for palliative care reached $8 \%$ of the total costs in Stockholm.

Methodologically, there is a potential gap between the hospital care costs calculated by DRGs and the actual costs of treatment episodes from the hospital departments, particularly for prostate biopsies in the outpatient setting. The unit cost of a prostate biopsy including the physician visit based on DRG N75O (€664) is lower than that from the hospital departments (€1159 - €1789). This may be explained by several reasons. First, the DRG cost is based on the average cost per DRG code, which is calculated from the average cost for all care occasions. To control the budget, often there is a ceiling for the quantity of DRG points to be produced by each caregiver. If the ceiling is exceeded, less compensation will be given per point produced [61]. In summary, if the quantity of $\mathrm{N} 75 \mathrm{O}$ used is more than planned, the compensation for each $\mathrm{N} 75 \mathrm{O}$ could be lower than its real costs. Second, many regions in Sweden have lessened the importance on DRG as a reimbursement model, which possibly resulted in less accuracy in recording DRGs in the diagnoses and treatments $[61,62]$.

Ten percent of drug costs for treating $\mathrm{PCa}$ were hospital-based requisition drugs, which is lower than the average proportion of requisition drugs of the total cost of cancer drugs at 54\% [37]. This could partly be explained by the uptake of Enzalutamide since its introduction to Sweden in 2014. Enzalutamide accounted for $45 \%$ of the total PCa drug costs in Stockholm during
2016 and had a 97\% of its sales as prescribed drugs. Other drugs, dominated by the costs in the hospital, had very low sales in 2016. In addition, many cancer drugs are used for multiple indications, including non-cancer diseases. For the 13 substances treating $\mathrm{PCa}$, almost half were used for other indications. Due to limited data availability, we used data in 2012 from the PDR and data in 2014 from SEPR Corpus to obtain the proportion of usage by the indication of PCa. Given the increased prevalence of $\mathrm{PCa}$, there is a need to better characterise these costs by source of utilisation and by indication.

Comparing the proportion of costs for productivity losses with cost analyses of other disease areas such as depression (65\%), breast cancer (70\%), multiple sclerosis (79\%) and brain tumors (74\%) [63-66], the costs for productivity losses due to $\mathrm{PCa}$ accounted for a much lower share of the total costs. This pattern may be mainly explained by most $\mathrm{PCa}$ patients being over age 65 years. The estimated costs of productivity losses due to morbidity in 2016 were lower compared with estimates from the European study for 2009 [17]. The lower estimates can possibly be explained by a reduction in the average days of sick leave compensation from 90 days [67] in 2009 to 72 days in 2016 [53] of men in Sweden, or by a considerable decrease in the number of men compensated for early retirement by 36\% from 2009 to 2016 [53, 67]. Furthermore, the estimated costs of productivity losses due to premature mortality in 2016 were also lower than the costs in 2009. This may be explained by the fact that the European study assumed 79 years old as the age of retirement for all countries [17], which is 14 years later than the general age of retirement in Sweden. In addition, it can also be partly explained by an absolute reduction in the number of $\mathrm{PCa}$ deaths below age 65 years from 138 in 2009 to 94 in 2016 [49].

We used the human capital approach to estimate the value of the productivity losses. A common criticism of 
Table 4 Costs of managing prostate cancer by treatment pathway, 2016 (€)

\begin{tabular}{|c|c|c|}
\hline Module/Procedure & Unit cost $(€)$ base/alternative & Resource use base/alternat \\
\hline \multicolumn{3}{|l|}{ Diagnosis } \\
\hline \multicolumn{3}{|l|}{ PSA test at primary care } \\
\hline GP visit & 152 & \\
\hline PSA test analysis & 4 & \\
\hline \multicolumn{3}{|l|}{ Total costs/patient } \\
\hline \multicolumn{3}{|c|}{ Biopsy at outpatient care: w/o MRI } \\
\hline $\begin{array}{l}\text { Specialist and nurse } \\
\text { consultation }\end{array}$ & 147 & \\
\hline Ultrasound & $151 / 212$ & \\
\hline Biopsy & 304 & \\
\hline Pathology & 516 & \\
\hline Nurse consultation & 40 & \\
\hline
\end{tabular}

Total costs/patient

Biopsy at outpatient care: with MRI

Specialist and nurse

consultation

Ultrasound

MRI

Biopsy

Pathology

Nurse consultation

Total costs/patient

\section{Treatment}

Active surveillance at outpatient care: w/o MRI

Specialist and nurse

consultation

PSA test sampling

PSA test analysis

Ultrasound

Biopsy

Pathology

Total costs/patient

Active surveillance at outpatient care: with MRI

Specialist and nurse

consultation

PSA test sampling

PSA test analysis

Ultrasound

MRI

Biopsy

Pathology

Total costs/patient

Radical prostatectomy at inpatient care: open surgery

Open surgery

Specialist and nurse consultation
$151 / 212$

354 / 569

304

0.2

1

1

1

1

1

1

147

40

147

36

4

151

304

516

147

36

4

151

354 / 569

304

516

147 Cost/patient (€) base/alternative Source/Remarks 
Table 4 Costs of managing prostate cancer by treatment pathway, 2016 ( $€$ ) (Continued)

\begin{tabular}{|c|c|c|c|c|}
\hline Module/Procedure & Unit cost $(€)$ base/alternative & Resource use base/alternative & Cost/patient (€) base/alternative & Source/Remarks \\
\hline RT & 672 & 0.25 & 168 & [12] \\
\hline Total costs/patient & & & $7738 / 7885$ & \\
\hline \multicolumn{5}{|c|}{ Radical prostatectomy at inpatient care: robot-assistant } \\
\hline Robot assisted surgery & $9941 / 12,328$ & 1 & $9941 / 12,328$ & {$[12]$} \\
\hline $\begin{array}{l}\text { Specialist and nurse } \\
\text { consultation }\end{array}$ & 147 & $1 / 2$ & $147 / 295$ & {$[73]$} \\
\hline RT & 672 & 0.25 & 168 & {$[12]$} \\
\hline Total costs/patient & & & $10,257 / 12,791$ & \\
\hline \multicolumn{5}{|c|}{ Radiation therapy at outpatient care } \\
\hline Oncologist - new visit & 397 & 1 & 397 & {$[32]$} \\
\hline Oncologist - further visit & 171 & 1 & 171 & {$[32]$} \\
\hline Nurse consultation & 40 & 20 & 808 & {$[73]$} \\
\hline RT & 672 & 20 & 13,440 & {$[12][75]$} \\
\hline Hormone therapy-annual & 6867 & 0.20 & 1373 & \\
\hline Total costs/patient & & & 16,189 & \\
\hline \multicolumn{5}{|c|}{ Metastatic: Chemo + Hormone therapy } \\
\hline Annual cost/patient & 7283 & 1 & 7283 & Results of study \\
\hline Total costs/patient & & & 7283 & Annual costs \\
\hline \multicolumn{5}{|l|}{ Metastatic: Hormone therapy } \\
\hline Annual cost/patient & 6867 & 1 & 6867 & Results of study \\
\hline Total costs/patient & & & 2136 & Annual costs \\
\hline \multicolumn{5}{|l|}{ Post treatment follow-up } \\
\hline \multicolumn{5}{|c|}{ Post treatment follow-up: Low/intermediate risk } \\
\hline $\begin{array}{l}\text { Specialist and nurse } \\
\text { consultation }\end{array}$ & 147 & 1 & 147 & [73] \\
\hline $\begin{array}{l}\text { Specialist consultation - Tele } \\
\text { follow-up }\end{array}$ & 15 & 11 & 162 & [73] \\
\hline PSA test sampling & 36 & 12 & 432 & {$[29]$} \\
\hline PSA test analysis & 4 & 12 & 46 & {$[33]$} \\
\hline Total costs/patient & & & 788 & \\
\hline \multicolumn{5}{|c|}{ Post treatment follow-up: High risk } \\
\hline $\begin{array}{l}\text { Specialist and nurse } \\
\text { consultation }\end{array}$ & 147 & 1 & 147 & [73] \\
\hline $\begin{array}{l}\text { Specialist consultation - Tele } \\
\text { follow-up }\end{array}$ & 15 & 14 & 206 & [73] \\
\hline PSA test sampling & 36 & 15 & 541 & {$[29]$} \\
\hline PSA test analysis & 4 & 15 & 57 & [33] \\
\hline Total costs/patient & & & 952 & \\
\hline
\end{tabular}

GP General Practitioner, MRI Magnetic Resonance Imaging, PSA Prostate-specific Antigen, RT Radiation Therapy

this approach is that it discriminates against those elderly individuals who are not within a working age. One may argue that patients at age 65 years or over would produce housework, babysitting of grandchildren, voluntary work or other unpaid productivity [22]. This criticism is especially relevant when estimating indirect costs for $\mathrm{PCa}$, since the majority of $\mathrm{PCa}$ patients are of retirement age. An alternative way of measuring the productivity losses is the friction cost method [24]. This approach, which measures the productivity loss due to an absent worker, provides a lower bound on these values compared with the human capital method. The friction cost method has been criticised since it does not consider the replacement cost for an absent worker or 
the loss in team productivity $[68,69]$. Note that this method also does not include patients aged 65 years and over.

Informal care was measured in terms of productivity losses of the caregiver prior to age 65 years as an opportunity cost, which is the most commonly used method in measuring costs for informal care [55, 70]. It could be argued that all caregivers, irrespective of their age, possibly used leisure time to provide care. There was a lack of data on whether the caregivers reduced their work time to provide informal care. However, leisure time is usually difficult to value and can be valued as being zero, as rates reflecting "home pay" or the market value for caregivers, or as overtime earnings [50, 57, 58]. We used the proxy good method to value informal care in a sensitivity analysis. The unit cost of nursing services was applied as a proxy and was similar to the general population. However, the estimation of care-time was considerably higher. Other researchers have observed that these two methods can yield widely varying estimates of care-time [70, 71].

It should be noted some costs due to palliative care, informal care and productivity losses can be associated with comorbidities, such as chronic diseases or concurrent diagnoses of other cancers. In this study, palliative care and productivity losses due to mortality were assigned based on primary cause of death. Informal care and productivity losses due to morbidity were assigned based on primary cancer diagnosis. It can be argued that PCa patients with comorbidities could lead to reduced PCa-related costs, because PCa patients might receive palliative care such as relieving pains caused by multiple diseases or take sick leave due to multiple diagnoses.

\section{Strengths and limitations}

To our knowledge, this is the first COI study of PCa in Stockholm. This study has a number of strengths. First, it provides a detailed description of resource utilisation and unit costs using the linked Swedish health and population registers. In particular, we carefully characterised the treatment pathways by resource type and the frequency of resource utilisation for combinations of diagnostic tests and treatment modalities for $\mathrm{PCa}$ patients. Second, this study provides all substances and reported the costs of both prescribed and requisition drugs treating $\mathrm{PCa}$ patients. This improves on earlier COI studies for Sweden $[17,18]$. Third, the PSA data from SPBR linked with PCa diagnosis allowed for a population-based description of PCa testing in the primary care setting. Fourth, the productivity losses were calculated using a general annual gross earnings for both genders during 2016 in Sweden to account for equity issues. Finally, the sensitivity analyses reflect how the uncertainties may have affected the results.
Some limitations should also be noted. Firstly, extrapolating data on PCa prevalence and costs from the Stockholm region to the national level could be less reliable. However, the general patterns for $\mathrm{PCa}$ incidence and mortality in Stockholm region are similar to the national averages, the guidelines for prevention and treatment of $\mathrm{PCa}$ are national, and we have indirectly adjusted for differences in PCa testing by the adjustment for PCa prevalence. Second, there is no nationally representative price list and the reported DRG unit costs for Stockholm and Sweden may not represent actual costs. Third, the SHARE study had approximately 37,000 and 1200 individuals responded to the survey in WAVE2 and WAVE3 for total 13 countries. This leads to a small sample size and a low statistical power for each country, especially for those who were severely limited in daily activities and who were terminally ill. Given this imprecision, one needs to be cautious in the interpretation of the estimates for informal care. Lastly, intangible costs, which value the loss of quality-adjusted life years for the affected patients, were not considered in this study.

\section{Implications for future economic evaluations}

While COI analyses are useful for providing cost estimates for the impact of certain diseases, they cannot serve as the sole evidence for priority setting in terms of funding and resource allocation for prevention and treatment. Health economic evaluations for priority setting generally include both costs and outcomes in terms of survival and quality of life associated with specific interventions [24]. In 2018, NBHW assessed the costeffectiveness of PCa screening on men aged 50-69 years in Sweden. Screening with the PSA test was considered to be cost-effective compared with no screening, but the assessment did not consider utilisation of new tests and complementary diagnostic tools and there was uncertainty for some key assumptions [29]. Due to these uncertainties, NBHW called for new economic evaluations of PCa screening using the new tests [29]. The resource and costs data from our study provide a reference for future economic evaluations to make informed decisions on whether to recommend a PCa screening program in Sweden. The values can also be used for economic evaluations for PCa therapies.

\section{Conclusion}

The economic burden due to PCa was substantial and constitutes a major public health problem in Sweden. The two main cost drivers were direct medical care and informal care, which represent 58 and $32 \%$ of the total costs, respectively. The cost data in this study provide reference values for future economic evaluations for policy decisions to address the increasing public health problem of $\mathrm{PCa}$. 


\section{Supplementary information}

Supplementary information accompanies this paper at https://doi.org/10. 1186/s12913-020-05265-8.

Additional file 1 Appendix A. Combinations of ICD-10 codes and DRGs for health events identification in inpatient and outpatient care, Sweden. Appendix B. Drugs treating prostate cancer in Sweden. Appendix C. Palliative care. Appendix D. Informal care. Appendix E Productivity losses due to premature mortality. Appendix F1. Total prevalence, incidence and mortality of prostate cancer in Stockholm and Sweden. Appendix F2. Prevalence of prostate cancer by age group, Stockholm Region and Sweden, 2016. Appendix G. Acknowledgement to SHARE.

\section{Abbreviations}

AS: Active Surveillance; ATC: Anatomical Therapeutic Chemical Classification System; COI: Cost-of-IIIness; CPI: Consumer Price Index; DRE: Digital Rectal Examination; DRG: Diagnosis-Related Group; FSK: Swedish Social Insurance Agency; GP: General Practitioner; ICD-10: The International Classification of Diseases, 10th version; Mn: Million; MRI: Magnetic Resonance Imaging; NBHW: National Board of Health and Welfare; OR: Operation; PCa: Prostate Cancer; PDR: Prescribed Drug Register; PSA: Prostate-Specific Antigen; RP: Radical Prostatectomy; RT: Radiation Therapy; SCB: Statstics Sweden; SEPR Corpus: Stockholm Electronic Patient Records Corpus; SHARE: Survey of Health, Ageing and Retirement in Europe; SPBR: Stockholm PSA and Biopsy Register; SRPC: Swedish Register of Palliative Care; SRPL: Stockholm Region Price List; TLV: Dental and Pharmaceutical Benefits Agency; WW: Watching Waiting

\section{Acknowledgements}

We would like to give our thanks to: Staffan Lundström and Greger Fransson from Svenska Palliativregistret, and Hercules Dalianis and Rebecka Weegar from Stockholm University for their guidance; and Jan Chandra Engel from Danderyds Hospital and Markus Aly from Karolinska Hospital for discussions.

\section{Authors' contributions}

The study was conceptualised by SH, EÖ, EH and MC. The ethics and data application were performed by SH, ME and MC. HG and TN provided expert opinion on clinical practices. The data analyses were conducted by $\mathrm{SH}$ and MC. The initial draft was written by SH, EÖ, EH and MC. All authors contributed to the writing of the final manuscript. The author(s) read and approved the final manuscript.

\section{Funding}

Funding was received from the Swedish Research Council (MC: 2018-02526; ME: 2015-03292), Cancerfonden (MC: CAN 2018/539; ME CAN 2015/649 and CAN 2018/741), the Swedish eScience Research Centre (MC), NordForsk (MC) and Prostatacancerförbundet (MC). The funders had no role in study design, data collection and analysis, decision to publish, or preparation of the manuscript. Open access funding provided by Karolinska Institute.

\section{Availability of data and materials}

The raw data used to estimate the resource utilisation of inpatient, outpatient and primary care, as well as the proportion of prescribed drug uses for prostate cancer patients during 2016 are available from the Stockholm PSA and Biopsy Register (SPBR). The aggregated prescribed and requisition drug costs data by substance level in 2016 from the Concise database that supported the data analyses of this study are available from the Swedish eHealth Agency. The data used to identify the proportion of prescribed drug uses of specific substances in 2012 for adult males are available from the Prescribed Drug Register (PDR). The data used to identify the proportion of requisition drug uses of specific substances prostate cancer patients are available from the Stockholm Electronic Patient Records Corpus (SEPR Corpus) Health Bank from Stockholm University. The data used to identify the resource utilisation of palliative care in the Stockholm region during 2016 are available from the Swedish Register of Palliative Care (SRPC). The data used to identify the resource utilisation of informal care of this study are available from the Survey of Health, Ageing and Retirement in Europe (SHARE) project. The data used to identify the workdays lost due to sick leave and early retirement of prostate cancer patients in the Stockholm region during 2016 are available from the Swedish Social Insurance Agency (FSK). Restrictions apply to the availability of these data, which were used under approval for the current study, and so are not publicly available. Anyone wishing to access the individual level data would need to apply for permission through an Ethical Review Board and from the primary data owners.

\section{Ethics approval and consent to participate}

Data from all registries and surveys were analysed with anonymised IDs in a secure environment. All data were accessed with ethical approvals from the Stockholm Regional Ethical Review Board (SPBR: dnr 2012/438-31/3, dnr 2016/620-32, dnr 2018/845-32, dnr 2018/1866-32; PDR: dnr 2009/5:10; SEPR Corpus Health Bank: 2014/1882-31/5). Record linkage for SPBR was undertaken by the National Board of Health and Welfare (Socialstyrelsen). Permissions to access data were provided by National Board of Health and Welfare (Socialstyrelsen), Karolinska Institutet, the Swedish Insurance Agency (Försäkringskassan) and the Swedish Palliative Register (Svenska Palliativregistret). Access to SEPR Corpus Health Bank was granted by Stockholm University. Access to aggregated data from the Concise Database was granted by the Swedish eHealth Agency (eHälsomyndigheten).

\section{Consent for publication}

Not applicable.

\section{Competing interests}

The authors declare that they have no competing interests.

\section{Author details}

'Department of Medical Epidemiology and Biostatistics, Karolinska Institutet, Nobels väg 12A, 17165 Stockholm, Sweden. 'Department of Women's and Children's Health, Karolinska Institutet, Tomtebodavägen 18A, 17177 Stockholm, Sweden. ${ }^{3}$ Department of Clinical Sciences, Danderyd Hospital, Mörbygårdsvägen, 18288 Danderyd, Sweden. ${ }^{4}$ Department of Learning, Informatics, Management and Ethics, Karolinska Institutet, Tomtebodavägen 18A, 17177 Stockholm, Sweden.

Received: 18 October 2019 Accepted: 28 April 2020

Published online: 20 May 2020

\section{References}

1. Bray F, Ferlay J, Soerjomataram I, Siegel RL, Torre LA, Jemal A. Global cancer statistics 2018: GLOBOCAN estimates of incidence and mortality worldwide for 36 cancers in 185 countries. CA Cancer J Clin. 2018;68(6):394-424.

2. Kvåle R, Myklebust T, Engholm G, Heinävaara S, Wist E, Møller B. Prostate and breast cancer in four Nordic countries: a comparison of incidence and mortality trends across countries and age groups 1975-2013. Int J Cancer. 2017;141(11):2228-42.

3. Kvåle R, Auvinen A, Adami HO, Klint A, Hernes E, Møller B, et al. Interpreting trends in prostate cancer incidence and mortality in the five Nordic countries. J Natl Cancer Inst. 2007;99(24):1881-7.

4. Ferlay J, Steliarova-Foucher E, Lortet-Tieulent J, Rosso S, Coebergh JW, Comber $\mathrm{H}$, et al. Cancer incidence and mortality patterns in Europe: estimates for 40 countries in 2012. Eur J Cancer. 2013;49(6):1374-403.

5. Cancer statistics for the Nordic countries [Internet]. Association of the Nordic Cancer Registries. 2017. Available from: http://www-dep.iarc.fr/ NORDCAN/English/frame.asp. Cited 2019 Mar 13.

6. Schröder FH, Hugosson J, Roobol MJ, Tammela TL, Zappa M, Nelen V, et al. Screening and prostate cancer mortality: results of the European randomised study of screening for prostate Cancer (ERSPC) at 13 years of follow-up. Lancet. 2014;384(9959):2027-35.

7. Hugosson J, Roobol MJ, Mansson M, Tammela TLJ, Zappa M, Nelen V, et al. A 16-yr follow-up of the European randomized study of screening for prostate Cancer. Eur Urol. 2019;76(1):43-51.

8. Schoots IG, Roobol MJ, Nieboer D, Bangma CH, Steyerberg EW, Hunink MG. Magnetic resonance imaging-targeted biopsy may enhance the diagnostic accuracy of significant prostate cancer detection compared to standard transrectal ultrasound-guided biopsy: a systematic review and meta-analysis. Eur Urol. 2015;68(3):438-50.

9. Kasivisvanathan V, Rannikko AS, Borghi M, Panebianco V, Mynderse LA, Vaarala $\mathrm{MH}$, et al. MRI-targeted or standard biopsy for prostate-Cancer diagnosis. N Engl J Med. 2018;378(19):1767-77. 
10. Regionalt cancercentrum i samverkan. Nationellt vårdprogram Prostatacancer. Regionalt cancercentrum Uppsala Örebro; 2017.

11. RATTEN - Interactive On Line Report from NPCR [Internet]. The National Prostate Cancer Register of Sweden and Prostate Cancer Database Sweden. 2019. Available from: https://statistik.incanet.se/npcr/. Cited 2019 Mar 18.

12. Socialstyrelsen. Hälsoekonomiskt underlag. Nationella riktlinjer för prostatacancer 2014. Socialstyrelsen; 2014.

13. Carlsson $\mathrm{P}$, Hjertberg $H$, Jonsson B, Varenhorst $E$. The cost of prostatic cancer in a defined population. Scand J Urol Nephrol. 1989;23(2):93-6.

14. Holmberg H, Carlsson P, Kalman D, Varenhorst E. Impact on health service costs of medical technologies used in management of prostatic cancer. Scand J Urol Nephrol. 1998;32(3):195-9.

15. Sennfält K, Sandblom G, Carlsson P, Varenhorst E. Costs and effects of prostate cancer screening in Sweden a 15-year follow-up of a randomized trial. Scand J Urol Nephrol. 2004;38(4):291-8.

16. Norlund A, Alvegard T, Lithman T, Merlo J, Noreen D. Prostate cancer-prevalence-based healthcare costs. Scand J Urol Nephrol. 2003;37(5):371-5.

17. Luengo-Fernandez R, Leal J, Gray A, Sullivan R. Economic burden of cancer across the European Union: a population-based cost analysis. Lancet Oncol. 2013;14(12):1165-74.

18. Lundqvist A, Andersson E, Carlsson K. Kostnader för cancer i Sverige idag och år 2040: IHE. Lund: IHE Rapport 2016:1;2016.

19. Tandvårds- och läkemedelsförmånsverket. Tandvårds- och läkemedelsförmånsverkets allmänna råd. Stockholm: Tandvårds- och läkemedelsförmånsverket; 2017.

20. Rice DP. Estimating the cost of illness. Am J Public Health Nations Health. 1967;57(3):424-40.

21. Hodgson TA. Costs of illness in cost-effectiveness analysis. A review of the methodology. PharmacoEconomics. 1994;6(6):536-52.

22. Larg A, Moss JR. Cost-of-illness studies: a guide to critical evaluation. PharmacoEconomics. 2011;29(8):653-71.

23. Jo C. Cost-of-illness studies: concepts, scopes, and methods. Clin Mol Hepatol. 2014;20(4):327-37.

24. Drummond MF, Sculpher MJ, Claxton K, Stoddart GL, Torrance GW. Methods for the economic evaluation of health care programmes. 3rd ed. New York: Oxford University Press; 2015

25. Statistics Sweden. Consumer Price index (CPI): statistics Sweden; 2019. Available from: https://www.scb.se/en/finding-statistics/statistics-by-subjectarea/prices-and-consumption/. Cited 2019 Mar 21.

26. Riksbanken. Årsgenomsnitt valutakurser (ackumulerat), Sök räntor \& valutakurser, Statistik 2019. Available from: https://www.riksbank.se/sv/statistik/ sok-rantor\%2D\%2Dvalutakurser/arsgenomsnitt-valutakurser/. Cited 2019 May 8.

27. Nordstrom T, Aly M, Clements MS, Weibull CE, Adolfsson J, Gronberg H. Prostate-specific antigen (PSA) testing is prevalent and increasing in Stockholm County, Sweden, despite no recommendations for PSA screening: results from a population-based study, 2003-2011. Eur Urol. 2013;63(3):419-25.

28. Samverkansnämnden Stockholm-Gotland. Referensvikter för slutenvård- och öppenvårdsgrupper, NordDRG 2016: Samverkansnämnden StockholmGotland; 2016. Available from: https://sthlm-gotland.se/wp-content/ uploads/2015/11/Bilaga-1-Utomla\%CC\%88nsprislista-Sluten-och-o\%CC\% 88ppenva\%CC\%8Ard-2016.pdf. Cited 2019 Mar 21.

29. Socialstyrelsen. Screening för prostatacancer med PSA-prov. Hälsoekonomisk analys Bilaga. Stockholm: Socialstyrelsen; 2018

30. Socialstyrelsen. Öppna jämförelser 2015 Hälso- och sjukvård: Övergripande indikatorer. Stockholm: Socialstyrelsen; 2015.

31. SödraRegionvårdsnämnden. Regionala priser och ersättningar för södra sjukvårdsregionen 2015. Lund: Södra Regionvårdsnämnden; 2015.

32. SödraRegionvårdsnämnden. Regionala priser och ersättningar för södra sjukvårdsregionen 2016. Lund: Södra Regionvårdsnämnden; 2016.

33. Region Stockholm. Temporära avtal avseende tjänster inom klinisk laboratoriemedici. Stockholm: Stockholms Läns Landsting; 2017.

34. National cancer institute. Drugs approved for prostate cancer: National cancer institute; 2018. Available from: https://www.cancer.gov/about-cancer/ treatment/drugs/prostate. Updated 2018 Jun 13; cited 2018 Jul 1.

35. Medicines. European Medicines Agency. 2018. Available from: https://www. ema.europa.eu/en/medicines. Cited 2019 Apr 10.

36. FASS. Farmaceutiska Specialiteter i Sverige. 2018. Available from: https:// www.fass.se/LIF/startpage. Cited 2019 Mar 21.

37. Vårdanalys. Cancerläkemedel - ett kunskapsunderlag om införande, användning och uppföljning. Stockholm: The Swedish Agency for Health and Care Services Analysis; 2017.
38. Dalianis $H$, Hassel M, Velupillai S. The Stockholm EPR Corpus Characteristics and Some Initial Findings. In: Proceedings of ISHIMR 2009, 14th international symposium for health information management research, Kalmar; 2009.

39. Dalianis H, Henriksson A, Kvist M, Velupillai S, Weegar R, editors. HEALTH BANK-A Workbench for Data Science Applications in Healthcare. CAiSE Industry Track; 2015. Sweden: Stockholm; 2015.

40. Läkemedel [Internet]. Tandvårds- och läkemedelsförmånsverket. 2018. Available from: https://www.tlv.se/beslut/sok-i-databasen.html. Cited 2018 Jul 1.

41. Martinsson L, Heedman PA, Lundstrom S, Axelsson B. Improved data validity in the Swedish register of palliative care. PLoS One. 2017;12(10):e0186804

42. Hjelmgren J, Ceberg J, Persson U, Alvegård TA. The cost of treating pancreatic Cancer. Acta Oncol. 2003:42(3):218-26.

43. Dahlberg L, Lundkvist J, Lindman $\mathrm{H}$. Health care costs for treatment of disseminated breast cancer. Eur J Cancer. 2009:45(11):1987-91.

44. Sahlen KG, Boman K, Brannstrom M. A cost-effectiveness study of personcentered integrated heart failure and palliative home care: based on a randomized controlled trial. Palliat Med. 2016;30(3):296-302.

45. SRPC. The Swedish Register of Palliative Care (SRPC): SRPC; 2019. Available from: www.palliativ.se. Cited 2019 Aug 1.

46. Wettermark B, Hammar N, Fored CM, Leimanis A, Otterblad Olausson P, Bergman $U$, et al. The new Swedish prescribed drug register--opportunities for pharmacoepidemiological research and experience from the first six months. Pharmacoepidemiol Drug Saf. 2007;16(7):726-35.

47. Börsch-Supan A, Brandt M, Hunkler C, Kneip T, Korbmacher J, Malter F Schaan B, Stuck S, Zuber S. Data Resource Profile: The Survey of Health, Ageing and Retirement in Europe (SHARE). Int J Epidemiol. 2013. https://doi.org/10.1093/ije/dyt088.

48. Lönestrukturstatistik, hela ekonomin [Internet]. Statistics Sweden. 2019. Available from: http://www.statistikdatabasen.scb.se/pxweb/sv/ssd/START AM_AM0110_AM0110B/?rxid=be04f565-fb79-4a9a-bda4-4348a3ff6098. Cited 2019 May 21.

49. Statistical Database, Cause of Death [Internet]. Socialstyrelsen. Available from: https://sdb.socialstyrelsen.se/if_dor/val_eng.aspx. Cited 2019 Aug 17.

50. Gold M. Panel on cost-effectiveness in health and medicine. Med Care. 1996:34(12):DS197-DS9.

51. Carlgren F. Sociala avgifter över tid: ekonomifakta; 2019. Available from: https://www.ekonomifakta.se/Fakta/Skatter/Skatt-pa-arbete/Sociala-avgifterover-tid/. Updated 2019 Jan 24; cited 2019 Jun 28.

52. Hodgson TA, Meiners MR. Cost-of-illness methodology: a guide to current practices and procedures. Milbank Mem Fund Q Health Soc. 1982;60(3):429-62.

53. Försäkringskassan. Social Insurance in Figures 2017. Stockholm: Swedish Social Insurance Agency; 2017.

54. Pensionsmyndigheten. Garantipension 2019. Available from: https://www. pensionsmyndigheten.se/forsta-din-pension/sa-fungerar-pensionen/ garantipension-om-du-har-lag-pension. Updated 2019 Feb 19; cited 2019 Mar 1.

55. Landfeldt E, Zethraeus N, Lindgren P. Standardized questionnaire for the measurement, valuation, and estimation of costs of informal care based on the opportunity cost and proxy good method. Appl Health Econ Health Policy. 2019;17(1):15-24.

56. Drummond M, McGuire A. Economic evaluation in health care : merging theory with practice. Oxford: Oxford University Press; 2001.

57. Russell LB, Gold MR, Siegel JE, Daniels N, Weinstein MC. The role of costeffectiveness analysis in health and medicine. Panel on cost-effectiveness in health and medicine. JAMA. 1996:276(14):1172-7.

58. Sach TH, Whynes DK. Measuring indirect costs: is there a problem? Appl Health Econ Health Policy. 2003;2(3):135-9.

59. Regionalt cancercentrum i samverkan. Prostatacancer Nationellt vårdprogram. Uppsala: Regionalt cancercentrum Uppsala Örebro; 2019.

60. Nilsson GH, Månsson J, Åhlfeldt H, Gunnarsson R, Strender L-E. Patients, general practitioners, diseases and health problems in urban general practice: a cross-sectional study on electronic patient records. Prim Health Care Res. 2008;9(2):119-25

61. Lindgren P. Ersättningen och e-hälsan. Stockholm: Studieförbundet Näringsliv och Samhälle (SNS); 2019.

62. Ellegård LM, Glenngård A. Att visa tillit genom val av ersättningsmodell effekter av anslagsfinansiering i hälso- och sjukvården i Region Skåne. In: Bringselius L, editor. Styra och leda med tillit. Stockholm: Forskning och praktik: Forskningsantologi från Tillitsdelegationen; 2018.

63. Sobocki $\mathrm{P}$, Jönsson $B$, Angst J, Rehnberg C. Cost of depression in Europe. Ment Health Policy Econ. 2006;9(2):87-98. 
64. Lidgren M, Wilking N, Jönsson B. Cost of breast cancer in Sweden in 2002. Eur J Health Econ. 2007;8(1):5-15.

65. Henriksson F, Jönsson B. The economic cost of multiple sclerosis in Sweden in 1994. PharmacoEconomics. 1998;13(5 Pt 2):597-606.

66. Blomqvist $\mathrm{P}$, Lycke J, Strang $\mathrm{P}$, Törnqvist $\mathrm{H}$, Ekbom A. Brain tumours in Sweden 1996: care and costs. J Neurol Neurosurg Psychiatry. 2000;69(6):792-8.

67. Försäkringskassan. Social Insurance in Figures 2014. Stockholm: Swedish Social Insurance Agency; 2014.

68. Koopmanschap MA, Rutten FF, van Ineveld BM, van Roijen L. The friction cost method for measuring indirect costs of disease. J Health Econ. 1995; 14(2):171-89.

69. Nicholson S, Pauly MV, Polsky D, Sharda C, Szrek H, Berger ML. Measuring the effects of work loss on productivity with team production. Health Econ. 2006;15(2):111-23.

70. Oliva-Moreno J, Trapero-Bertran M, Pena-Longobardo LM, Del Pozo-Rubio R The valuation of informal Care in Cost-of-Illness Studies: a systematic review. PharmacoEconomics. 2017;35(3):331-45.

71. van den Berg B, Spauwen P. Measurement of informal care: an empirical study into the valid measurement of time spent on informal caregiving. Health Econ. 2006;15(5):447-60.

72. Socialstyrelsen. Öppna jämförelser 2014 Hälso- och sjukvårdHälso- och sjukvård. Jämförelser mellan landsting. Del 1. Övergripande indikatorer. Stockholm: Socialstyrelsen; 2014.

73. Region Stockholm. Vårdval specialiserad urologi. Stockholm: Stockholms läns landsting; 2018.

74. Karolinska Universitetssjukhuset. Karolinska Universitetssjukhuset Röntgen, Huddinge och Solna Prislista giltig från och med 2017-07-01. Karolinska Sjukhuset; 2017.

75. Akademiska sjukhuset. Strålbehandling. Available from: https://www. akademiska.se/for-patient-och-besokare/ditt-besok/undersokning/ prostatacancer/din-behandling/stralbehandling/. Cited 2019 Jun 19.

\section{Publisher's Note}

Springer Nature remains neutral with regard to jurisdictional claims in published maps and institutional affiliations.

Ready to submit your research? Choose BMC and benefit from:

- fast, convenient online submission

- thorough peer review by experienced researchers in your field

- rapid publication on acceptance

- support for research data, including large and complex data types

- gold Open Access which fosters wider collaboration and increased citations

- maximum visibility for your research: over $100 \mathrm{M}$ website views per year

At $\mathrm{BMC}$, research is always in progress.

Learn more biomedcentral.com/submissions 